\title{
OPORTUNIDADES E TRANSFORMAÇÃO NA CIDADE CENTRO
}

\author{
TEResa Barata SAlgueiro ${ }^{1}$
}

\begin{abstract}
Resumo - O objectivo deste texto é situar as transformações verificadas no ambiente construído das cidades, principalmente das suas áreas centrais, no quadro do desenvolvimento de novas procuras sociais e estratégias de transformação urbana. As dimensões privilegiadas são o aumento da diversidade das populações urbanas associado ao aumento da mobilidade e à importância do consumo, e alterações nas formas de gestão e governância urbana com incidências no desenvolvimento do sector imobiliário e na produção de espaços de qualidade.
\end{abstract}

Palavras-chave: Recomposição urbana, novas procuras sociais, nobilitação, grandes projectos.

\begin{abstract}
TRANSFORMATION AND OPPORTUNITIES IN THE INNER CITY. In this paper we wish to contribute towards the understanding of the built environment, transformation mainly in inner cities, in relation to the development of new social demands and new strategies for urban redevelopment.

The main argument is based upon the technological-economic component of globalisation, discussed along two main axes (fig. 1). The former is related to the modification of cities' economic base and their management; the latter concerns the movement of people and the emergence of new lifestyles.

Population growth, which brings new residents and visitors to cities, and changes in postmodern consumers' tastes, which are more concerned with the beautification of their surroundings, serve to influence the growth of the cultural economy and represent new opportunities for inner cities in terms of housing (gentrification), retail, urban revitalisation and events.

Economic globalisation and the development of neoliberal ideologies allow for different forms of competitiveness between territories and change in political issues. The importance of economic issues in policy orientation, the development of entrepreneurial types of urban management and coalitions between the public and the private sectors are just some examples of the transformation behind the huge investments in the built environment's transformation and re-imaging. Changes in urban management and governance strongly impact the real estate development of high quality projects.
\end{abstract}

1 Professora de Geografia na Faculdade de Letras da Universidade de Lisboa e investigadora do Centro de Estudos Geográficos de Lisboa. Fax: +351217960063; e-mail: tbs@fl.ul.pt 
Key words: Urban restructuring, redevelopment, new social demands, gentrification, consumption, mega-projects.

Résumé - OPPORTUNITÉS ET TRANSFORMATIONS DANS LES CENTRES VILLE. On cherche à situer les transformations subies par l'ensemble construit des villes, surtout dans la partie centrale de celles-ci, en fonction du développement des nouvelles demandes sociales et des stratégies de transformation urbaine. Les aspects principaux en sont: la diversité accrue des populations urbaines, associée à leur mobilité et à leur consommation croissantes, et la modification des formes de gestion et de gouvernance urbaines, qui se reflètent dans le développement du secteur immobilier et dans la production d'espaces de qualité.

Mots-clés: Recomposition urbaine, nouvelles demandes sociales, rénovation, grands projets.

\section{INTRODUÇÃO}

Com a aproximação do final do século XX muita coisa muda nas cidades. Registaram-se grandes transformações na estrutura económica e social, na organização espacial e na própria forma das cidades. Aliás a mudança é princípio essencial das sociedades modernas e aquilo que as distingue das anteriores (Ascher, 2004).

A transformação das áreas urbanas pode ser estudada segundo as duas dimensões para que aponta a etimologia, urbs e civitas, respectivamente, a dimensão material e a social, dialecticamente relacionadas. Ambas sofrem mudanças ao longo do tempo, hoje mais aceleradas, e que precisam de ser equacionadas à luz dos processos globais.

Urbs em latim significava um aglomerado com muralha, portanto individualizado do campo circundante e metaforicamente dotado da capacidade de defesa. Remete portanto para uma estrutura material delimitada e aposta no território. Deste ponto de vista, as grandes transformações contemporâneas dos aglomerados podem sintetizar-se em quatro linhas principais: a tendência para o crescimento das concentrações populacionais; a extensão periférica com dispersão e polarização; a reformulação das áreas interiores com esvaziamento e recolonização dos centros; e a construção de uma rede de centralidades.

Em termos sociais, a civitas, que vem do grego civis, refere-se à comunidade dos cidadãos, dos que tinham acesso à polis, à discussão e à decisão pelo voto, na Grécia clássica. (Grésillon, 1996; Phillipps, 1996). É a cidade vista como uma sociedade, comunidade de indivíduos ligados entre si e a um território por determinados laços, os objectivos e os modos de governo que nele se exercem. Nesta perspectiva, as linhas de transformação referem-se, principalmente, a alterações na estrutura demográfico-social, a novas formas de apropriação do espaço ou de territorialidade, a alterações nas formas de governo. Em termos demográfico-sociais, os aspectos mais relevantes da mudança dizem respeito ao envelhecimento, à expansão de novos modelos de famílias, à impor- 
tância das migrações, às novas características do mercado de trabalho, à diversidade étnico-cultural e de estilos de vida.

Com este texto pretendemos contribuir para uma leitura das transformações verificadas no ambiente construído das cidades, principalmente nas suas áreas centrais, à luz do desenvolvimento de novas procuras sociais e estratégias de transformação urbana. As dimensões privilegiadas são o aumento da diversidade das populações urbanas associado ao aumento da mobilidade, e alterações nas políticas e nas formas de governância urbana que definem o quadro que baliza e contextualiza as acções dos actores.

O nosso argumento baseia-se na componente tecnológico-política da globalização traduzida no aumento dos movimentos de pessoas, bens, capitais e informações, e desenvolve-se segundo duas linhas principais. A primeira referese ao movimento de pessoas e à emergência de novos estilos de vida, enquanto a segunda se prende com alterações na base económica das cidades e das formas do seu governo.

Os movimentos de pessoas cresceram muito em número e em variedade de duração, objecto, distância percorrida, entre outros. Uns decorrem no interior de uma mesma área urbana, outros ligam a cidade com territórios mais ou menos afastados, dentro do país ou à escala internacional. Todos nos importam mas principalmente os que se concentram nas áreas urbanas ou que trazem gente de fora até à cidade, contribuindo para o aumento da diversidade das populações urbanas. Esta é acentuada pela emergência de novos estilos de vida propiciados pela expansão da mobilidade e, indirectamente, do desenvolvimento das Tecnologias de Informação e Comunicação (TIC), que se expressam em novas demandas sociais e se traduzem em novas formas de apropriação do território. $\mathrm{O}$ aumento da mobilidade, que traz pessoas à cidade, associado à mudança nos gostos e na procura dos consumidores pósmodernos no sentido de uma estetização do seu quadro de vida, viabilizam o importante crescimento da economia cultural nas sociedades capitalistas avançadas e representam novas oportunidades para o centro, seja em termos de residência, seja de actividades e acontecimentos, mas podem também contribuir para aumentar os problemas de sustentabilidade.

A segunda linha de raciocínio prende-se com alterações na base económica das cidades e das formas do seu governo. A globalização da economia, em paralelo com o crescimento das ideologias neoliberais, está na base do aumento da concorrência entre territórios e de uma inflexão na governância. De facto, a globalização associada ao aumento das mobilidades tem duas consequências importantes, para a nossa análise: por um lado, a perda de importância dos factores tradicionais de localização baseados em características locais (as vantagens comparativas) e, por outro lado, a internacionalização do mercado imobiliário. A primeira favorece a relocalização das actividades económicas, o que determina uma fragilização acrescida dos territórios onde a deslocalização acarreta encerramento de unidades e desemprego, e o aumento da concorrência entre territórios. Ao mesmo tempo, cresce a importância dos factores de carácter não económico, isto é, sociais, culturais, políticos e ambientais, o que está directamente 
na base de novas políticas e das novas formas de fazer a gestão urbana. No domínio das políticas é de salientar a importância assumida pelos objectivos económicos de atrair investimentos e visitantes, enquanto na governância urbana se verifica uma alteração no papel do Estado, o papel crescente das organizações da sociedade civil e das parcerias público-privadas.

A facilidade do movimento de capitais, a mobilidade acrescida das empresas e pessoas e a valorização do ambiente construído, seja por razões funcionais ou estéticas, o aumento de escala nas operações de promoção urbanística, com a construção de megaprojectos, propiciam o desenvolvimento e a internacionalização do mercado imobiliário, ou pelo menos de alguns dos seus segmentos. Deste modo, na figura 1 estabelecemos as relações que balizam o essencial da nossa análise.

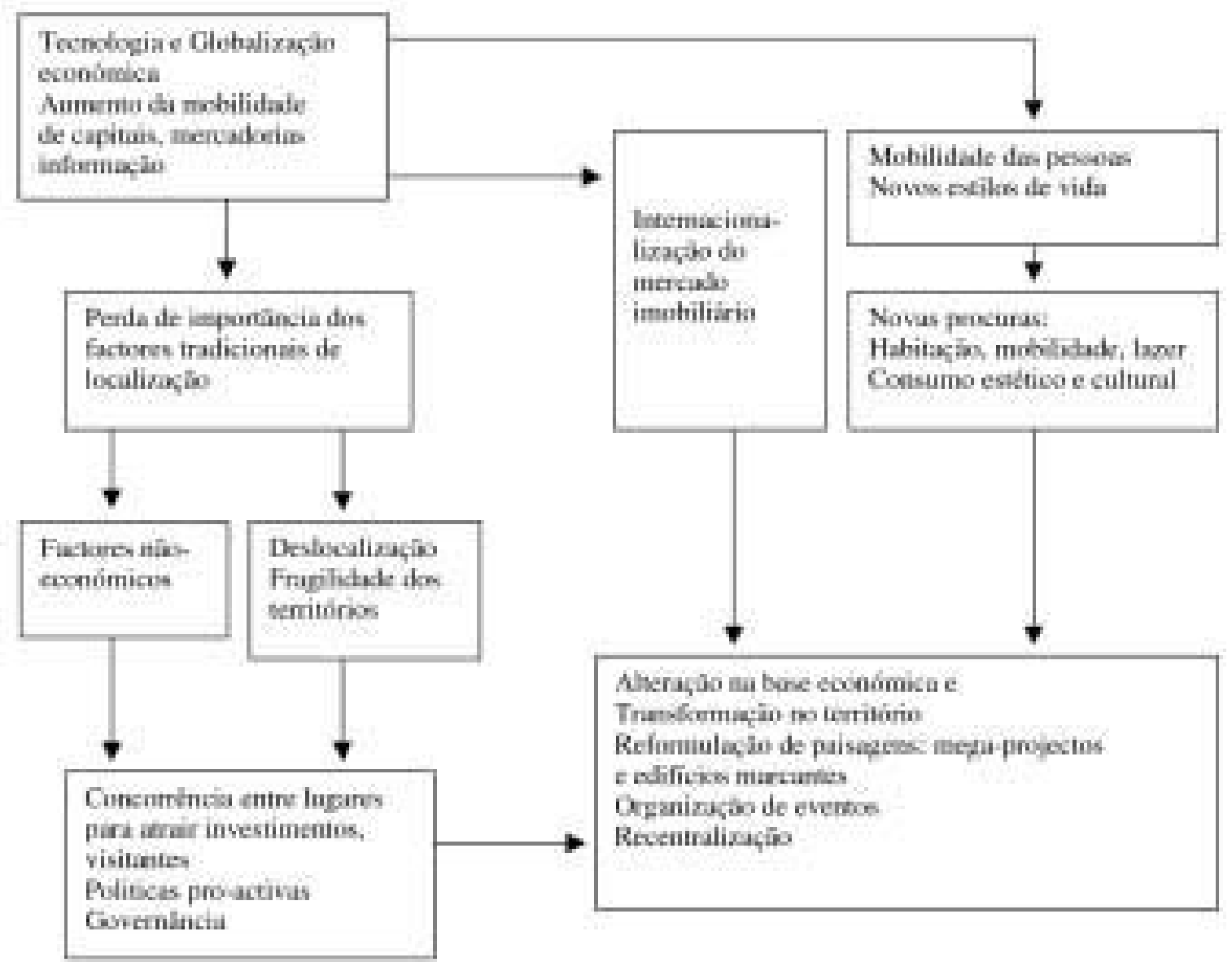

Fig. 1 - Esquema de análise

Fig. 1 - Theoretical approach

Assim, depois desta introdução, em que enunciamos o essencial das alterações no ambiente construído, passamos à consideração de algumas mudanças sociais, as que se prendem com o aumento da mobilidade, o novo papel do consumo e o aumento da diversidade de estilos de vida, nas áreas urbanas, por nos parecerem os mais relevantes na composição da nova procura para as áreas centrais. Deixamos de fora da análise a procura das empresas, em parte já abordada em texto anterior (Barata Salgueiro, 1992). Na terceira parte debruçamo- 
nos sobre a produção de espaços de qualidade e mostramos como ela é também produto da nova forma de governância nas áreas urbanas.

Em termos de ambiente construído retomamos as quatro linhas de transformação acima enunciadas, embora de forma resumida, apenas para ajudar a contextualizar a análise. O desenvolvimento das tecnologias de informação e de transporte e utopias de que a comunicação substituiria as deslocações, viabilizando um padrão de povoamento totalmente disperso, permitiram anunciar o fim das cidades, pelo menos tal como até agora as conhecemos. $\mathrm{Na}$ realidade, continua a reforçar-se a aglomeração, as cidades continuam a crescer, a ser cada vez maiores. A progressiva tendência para o crescimento das concentrações populacionais vem dando origem a cidades muito populosas, o que permite, desde há poucos anos, encontrar na literatura especializada a referência a megacidades, isto é, aglomerados com mais de 8 ou 10 milhões de habitantes. Este crescimento traduz-se numa grande extensão da superfície construída, pela ocupação de territórios vastos para lá dos limites da velha aglomeração.

$\mathrm{O}$ desenvolvimento dos transportes e comunicações libertou muitas actividades da necessidade de localizações centrais. O mesmo sucede com as residências, uma vez que aumentou o nível de rendimentos e a taxa de motorização das famílias. O automóvel trouxe o enorme crescimento suburbano do século XX e as cidades com limites cada vez mais indefinidos, fenómeno que se acentuou nos últimos anos. A dispersão típica da cidade norte-americana do pós-guerra, quando se deram incentivos aos veteranos do conflito para adquirir casa nos subúrbios, estendeu-se às nossas cidades nos anos 60, principalmente, por via da construção clandestina, numa época de intensa migração campo-cidade e fortes bloqueios no mercado habitacional, para hoje ganhar estatuto de cidadania. $\mathrm{O}$ aumento dos rendimentos e do consumo permite a cada vez maior número de famílias aspirar à posse de casa própria, independente, com jardim e mais alguns atributos significantes de standing: garagem, barbecue, piscina. $\mathrm{O}$ consumo de espaço que isto exige não se compadece com bairros de elevado preço do terreno nem as grandes áreas de alojamento, agora na moda, se encontram nos fogos existentes nas áreas interiores das cidades, que só complicados processos de emparcelamento permitiriam oferecer. Deste modo, as novas procuras em termos de habitar são também um estímulo ao movimento para os subúrbios.

A extensão periférica acentua-se com o aumento da mobilidade e do tempo livre, faz-se também com habitação secundária e por uma diversificação dos usos de solo. Ao lado de ocupações tradicionais de subúrbio, representadas pela residência e por actividades económicas de tipo industrial e de armazenagem, surgem diversos usos que são grandes consumidores de terreno, com destaque para as infra-estruturas de transporte e logística, áreas verdes, mais ou menos protegidas, espaços de lazer, como campos de golfe e recintos desportivos de vários tipos, complexos comerciais, dos hipermercados aos centros comerciais regionais, passando pelos retail parks, e centros de escritórios que contribuem para a definição de uma rede de centralidades que polariza os vastos territórios da periferia. Neste quadro, o aumento da área urbanizada tem sido superior ao 
do crescimento demográfico, o que significa que o consumo por residente tem aumentado; ao mesmo tempo a forma urbana está a modificar-se.

As áreas urbanas são palco de processos divergentes de concentração e desconcentração. A um nível macro concentram volume importante de pessoas e actividades, mas a níveis mais detalhados os padrões de ocupação do território revelam sinais de dispersão sobre extensas áreas, embora não uniformemente. A literatura dá conta de corredores ou sectores privilegiados e da existência de polarizações, local points of dispersed reconcentration (Hall, 2003). No que toca à diversidade funcional, de centro de emprego e oferta de serviços, a cidade reconstituiu-se no exterior, o que levou Garreau (1991) a falar em edge cities e Soja (1994) em cidades exteriores ou exopolis, dando origem a um novo arquétipo para a forma urbana (Hall, 2003) e permitindo a desconstrução e reconstrução dos conceitos de cidade e subúrbio. As tendências enunciadas obrigam pois a reproblematizar o conceito de cidade e explicam o aparecimento de expressões alternativas como metapolis ou "cidades pósmodernas" e muitas outras mais explicitamente referentes à forma urbana e à urbanização como processo de organização, de que são exemplo as «cidades galácticas» (Lewis, 1983), as «cidades arquipélago» (Viard, 1994), as «cidades fragmentadas» ou o «urbanismo estilhaçado» (Graham e Marvin, 2001).

Ao mesmo tempo que se assiste à extensão periférica, há alterações dos tecidos das áreas interiores: a cidade faz-se e refaz-se constantemente, pelo que surge como um palimpsesto, um livro escrito e reescrito vezes sem conta, uma sucessão de camadas sobrepostas e justapostas, uma vez que cada geração adapta o que herda às necessidades do presente. As estruturas envelhecem, degradam-se, apresentam-se desadaptadas às necessidades novas, são reconvertidas ou substituídas.

O esvaziamento e recolonização dos centros é a melhor prova de que a paisagem urbana muda incessantemente. De facto, falar de esvaziamento dos centros significa a saída de algumas funções da área central o que, em muitas cidades, trouxe graves problema ao nível da quebra do emprego e de residentes. Verifica-se a diminuição do número de fogos substituídos por escritórios e comércios, processo conhecido por terciarização e responsável pela diminuição do número de residentes e formação dos centros de negócios, empresariais, comerciais e financeiros. A cidade das empresas, com a sua arquitectura particular, consolida-se nos centros renovados ou nas áreas de expansão dos centros, desde os anos 60 do século passado. A área central torna-se o destino diário de milhares de empregados de escritório, tal como dos administradores de empresas e do pessoal responsável pelas limpezas, segurança e manutenção das organizações. Também aqui proliferam os escritórios de serviços de apoio especializado às empresas (jurídico, financeiro, de contabilidade, informático, marketing e publicidade, etc $)^{2}$ e os serviços de apoio à numerosa população empregada num processo cumulativo de multiplicação de actividades. Com cidades e

2 Ver, por exemplo, para Lisboa e Porto, Ferrão e Domingues, 1994. 
economia em crescimento, o comércio é igualmente uma actividade em expansão: aumenta o número de estabelecimentos e complexifica-se a estrutura comercial, numa hierarquia de níveis polarizada pelo centro principal da aglomeração. Justaposto ou confundido com o centro empresarial e de negócios, afirma-se o centro comercial onde se encontram os artigos mais raros cuja lojas atraem clientelas distantes. Também na área central se encontra uma zona de diversões com forte atractividade e, em áreas específicas da cidade centro, surgem indústrias responsáveis por percentagem importante do emprego da aglomeração.

A indústria e a residência foram as primeiras actividades urbanas a revelar padrões de localização mistos no sentido em que se encontram na cidade centro e nos bairros periféricos. O que precipita a recomposição urbana do último quartel do século Xx é, no entanto, a deslocalização de grande número de empresas industriais, às vezes a grande distância, o declínio de importantes áreas ligadas aos transportes e o encerramento de armazéns conexos, a saída maciça de residentes das áreas interiores, a instalação periférica de importantes centros empresariais e de comércio. Estes processos tiveram como consequências a perda e envelhecimento da população da cidade centro, no contexto metropolitano, o declínio no número de postos de trabalho, o abandono e degradação de muitos edifícios e de extensas áreas, a perda da hegemonia em termos comerciais e de prestação de serviços do antigo centro, e a construção de uma estrutura de centralidades responsável por metrópoles policêntricas.

A rede de centralidades que caracteriza as actuais áreas urbanas é uma consequência dos processos descritos de mudança: o centro não é mais o que costumava ser e as periferias desenvolveram-se e adquiriram muitas funções anteriormente características do centro, tal como as áreas intermédias. Deste modo, em territórios vastos onde se dispersam as actuais metrópoles individualizamse áreas com especialidades diversas, bairros dormitórios, concentrações de emprego, às vezes muito especializado, zonas de compras e de lazer entre as quais se partilham as deslocações dos citadinos, numa rede mais complexa e volátil de escolhas. Estas novas centralidades são espaços de grande valor pela sua localização, pela qualidade e pelo prestígio do sítio e dos edifícios; são os sítios mais adequados para os negócios, que oferecem maior qualidade de vida às famílias, que propiciam maiores economias. Fonte apetecível de acumulação de capital, atraem investimentos e empresas. Numa sociedade intensiva em informação e conhecimento, as TIC, as conexões rápidas e outros sistemas de infraestruturas, são cruciais na valorização, pelo que estes projectos são, no geral, mais bem servidos do que o resto da cidade.

\section{MIGRAÇÕES, ESTILOS DE VIDA E NOVAS OPORTUNIDADES PARA AS ÁREAS CENTRAIS}

A cidade foi sempre caracterizada pela diversidade, tanto das estruturas edificadas, como dos tecidos sociais. A variedade de ocupações, traduzida na 
presença dos primeiros especialistas (empenhados em tarefas outras que a procura de alimentos), é um dos critérios usados pelos historiadores para identificar as primeiras cidades. A diversidade diz também respeito à origem ou pertença étnica e cultural, e dos estilos de vida. Hoje em dia verifica-se um aumento das diferenças sociais e funcionais nas áreas urbanas, com o progresso das migrações transnacionais, a multiplicação das actividades, designadamente no vasto campo dos serviços, e a emergência de uma pluralidade de estilos de vida associados à transformação da sociedade de consumo.

As migrações foram sempre importantes para o crescimento das urbes a ponto de White (2002) afirmar mesmo que «as cidades são produto das migrações». As cidades alimentaram-se à custa de populações dos arredores que traziam a sua produção ao mercado e muitas vezes aí se fixavam. Grande parte da explosão urbana do século xx é produto do êxodo rural que levou enormes massas de camponeses em direcção às cidades em busca de trabalho. Essa atracção foi-se estendendo, pelo que a área de recrutamento, para muitas cidades, é hoje o mundo.

Nesta «era das migrações», como lhe chama Castles e Miller (2003), num «mundo de mobilidades» em que todos os lugares recebem fluxos crescentes de capitais, de mercadorias, de produtos culturais e de pessoas, através de fronteiras que se apresentam cada vez «mais porosas» (Castles, 2005), tem havido uma verdadeira explosão dos movimentos de pessoas, concretamente daquelas que têm o estatuto de imigrante, e este movimento está a afectar as cidades e os territórios.

Nos países da América constituíram-se cidades pluriculturais e pluri-étnicas nos séculos XIX e XX devido à migração maciça de povos europeus, e depois asiáticos, que completou a migração forçada dos africanos dos séculos precedentes e que então convergiram também nalgumas cidades. Na segunda metade do século XX este carácter multi-étnico e multicultural estende-se aos países da Europa que passam a acolher populações dos territórios dos ex-impérios, que entretanto acederam à independência e viram-se, muitas vezes, envolvidos em guerras, pessoas de outros países extra-europeus e mesmo da Europa (primeiro do Sul e actualmente do Leste).

O que diferencia as migrações actuais, posteriores à segunda grande guerra mas principalmente dos últimos vinte e cinco anos, das anteriores, é a sua globalização, a aceleração dos volumes envolvidos, o crescimento da diferenciação e o aumento da feminização. Com efeito, assiste-se a uma globalização do fenómeno migratório, pois os movimentos não se limitam a um continente, como sucedeu ao processo na Europa, do Sul para o Centro e Norte, no interior da Ásia ou do México para os Estados Unidos da América, nem à travessia oceânica da Europa para a América ou da Ásia para a América, mas generalizamse em termos de origem e de destino. A América do Norte, a Europa e mesmo a Austrália, são agora as maiores áreas de destino, enquanto a origem principal compreende a Ásia, a África e a América do Sul.

$\mathrm{O}$ aumento das mobilidades traduz-se no crescimento de todo o tipo de movimentos de pessoas, desde os de pequeno raio às migrações internacionais, 
desde os determinados pelo trabalho e pelo estudo, aos de lazer e relacionados com a passagem à reforma. Nos movimentos de trabalho há uma grande diferença entre os que envolvem quadros de empresas multinacionais ou transnacionais e que são enquadrados pela entidade empregadora, e os que partem da base, isto é, que dizem respeito a pessoas que migram em demanda de trabalho e de melhores condições de vida, embora ambos tenham crescido.

O movimento de estudantes, relevante para a nossa análise, envolve os do ensino superior, porque nos outros graus existe escola a nível local não implicando, portanto, outra deslocação para além da pendular. $O$ ensino superior está geograficamente concentrado e tem um nível de especialização e de selecção que justifica importantes fluxos de estudantes em vários sentidos. A Europa conheceu cidades cujo desenvolvimento se deve à função universitária. Coimbra é disso exemplo à escala portuguesa. Nos últimos anos, multiplicaram-se as universidades e outras escolas superiores no país mas cresceu também, consideravelmente, o número de estudantes universitários e daqueles que vivem fora da região de origem, nos períodos escolares. Este movimento, que já tem alguma expressão, tenderá a acentuar-se a nível europeu com as reformas em curso. Em cidades médias, de 30 a 50 mil habitantes, uma universidade de 5 a 7 mil estudantes, grande parte dos quais vindo de fora, faz diferença: é uma população flutuante que se exprime em procuras específicas e contribui para alguma dinamização económica e cultural da vida urbana.

É sabido que os movimentos de turismo sofreram um crescimento brutal na segunda metade do século XX com a democratização das viagens de avião. Ao mesmo tempo, diversificaram-se os destinos que se fazem para distâncias cada vez maiores. Particularmente importante para as áreas urbanas são os movimentos de turismo cultural e de congressos e feiras, isto é, profissional. Na tentativa de captar visitantes, as "cidades" desenvolvem importantes campanhas de promoção e marketing que valorizam os seus recursos no domínio do património edificado, da gastronomia, da qualidade arquitectónica ou das condições para acolher profissionais. Para além das infra-estruturas adequadas a vários tipos de eventos, volume e qualidade do parque hoteleiro, o turismo profissional acaba também por valorizar os recursos patrimoniais e culturais.

A redução dos horários de trabalho e a alteração nas condições de trabalho, o aumento na mobilidade e nos rendimentos, bem como condições favoráveis de crédito propiciaram o crescimento das residências secundárias. Tradicionalmente situadas em áreas do litoral com praia ou nas terras de origem, começam a invadir outros tipos de ambiente: mundo rural, sítios naturais "puros", isolados ou abandonados por antigos residentes, como as aldeias da Lousã que Cravidão (1991) estudou e centros de cidades históricas com importante carga patrimonial. Um estudo sobre a procura de habitação na Area Metropolitana de Lisboa, entre 2003 e $2005^{3}$, mostra que a compra de segunda 
habitação representa já $14 \%$ das intenções de compra de habitação na cidade, contra $1,9 \%$ no conjunto da região metropolitana.

As migrações de reformados têm igualmente registado importante crescimento com o aumento da esperança de vida e diminuição da idade da reforma, bem como com a situação financeira mais desafogada propiciada pelo welfare state a estes grupos. Dirigem-se para as suas regiões de origem, quando fizeram a migração do campo no início da vida activa, para regiões aprazíveis, seguras e com bom clima ${ }^{4}$, mas começam também a orientar-se para pequenas e médias cidades, mesmo sem relação com a sua origem familiar. Deste modo constituem outro segmento das novas procuras nas áreas urbanas.

A chegada de forasteiros contribui para o aumento da população urbana, mesmo que sazonalmente, para o fortalecimento de laços com outras regiões, para a dinamização económica e cultural e cria novas procuras para o mercado de serviços local, constituindo uma oportunidade e um desafio à reestruturação da cidade, designadamente das suas áreas mais centrais.

Os estilos de vida estão associados aos valores, expectativas e aspirações das pessoas e grupos (Clark, 1996). O conceito de "estilo de vida urbano" evoluiu de componente relativamente estável do estatuto social dos indivíduos, tal como conceptualizado por Weber, para capital cultural que os indivíduos procuram alcançar e que encoraja formas de consumo cultural, na linha das ideias de Bourdieu, tendo fortes reflexos na economia e na paisagem urbanas (Zukin, 1998). O conceito de estilo de vida tem pois uma forte componente cultural e adquire hoje maior importância, quer na literatura académica, quer no discurso dos decisores, porque o crescimento das migrações trouxe para as cidades muito maior diversidade cultural e étnica, enquanto a ética pósmoderna é relativamente ecléctica e aberta à novidade e ao "outro", permitindo maior expressão de estilos de vida minoritários, seja de ordem cultural, sexual ou étnica. A afirmação dos estilos de vida e das identidades fazse, em larga medida, pelo consumo.

Depois de estarem preenchidas as necessidades básicas ou primárias, a evolução da sociedade de consumo trouxe o desenvolvimento de necessidades no domínio do lazer e da cultura, o consumo dos sentidos associados a objectos e situações. $\mathrm{O}$ consumo conspícuo aparece desde cedo ligado à estratificação social e a processos de emulação como Veblen ([1899], 1970) ou Campbell (1987) revelaram. Com o avanço da modernidade e o aumento da complexidade social, o consumo passa a desempenhar um papel decisivo na construção das identidades, como os trabalhos de Cachinho $(1996,1999,2006)$ mostram e as Ciências Sociais tomam maior consciência desse facto ${ }^{5}$. As pessoas expres-

4 Há muitos ingleses e alemães reformados a viver no Estoril e no Algarve.

5 Glennie (1998) nota uma importante evolução dos estudos sobre o consumo nas Ciências Sociais. Inicialmente o foco situava-se nas classes sociais e portanto o consumo exprime-as e identifica-se com elas. Nos finais do século Xx a maior diferenciação das pessoas leva os estudiosos a estudar o papel do consumo na construção das identidades. 
sam as várias identidades que hoje assumem ou fragmentos delas com recurso a diversos marcadores, desde os característicos do género, etnia, classe social, aos objectos, ambientes e estilos de vida. A emulação, a necessidade constante de novidades, a necessidade de representação permanente que Cachinho dá conta neste volume, a mudança pósmoderna que acentua as componentes estéticas propiciam o papel dos elementos culturais na distinção.

Há essencialmente dois conceitos de cultura, um vem da antropologia e refere-se a modos de vida, ao conjunto das práticas quotidianas que expressam e articulam um conjunto de valores com sentido; outro é estético, o de Cultura (com c maiúsculo), corresponde às artes e à sua apreciação por parte de elites educadas. Para estas existe um estilo de vida que expressa o valor da cultura por actos de consumo cultural de âmbito cada vez mais lato (Miles, 2005).

O aumento do consumo de "cultura" fomenta o desenvolvimento da economia simbólica que inclui os espaços onde estes bens são criados, produzidos e consumidos. Deste modo, a cultura e, indirectamente, os estilos de vida, articulam-se com a produção do ambiente construído. Se aceitarmos que os estilos de vida são «simultaneamente resultado e matéria prima do crescimento da economia simbólica», como diz Zukin (1998: 826), melhor se compreende a sua importância na economia urbana e a atenção dada aos estilos de vida e ao consumo cultural pelos gestores e produtores da cidade.

Para Yudice (2003) $)^{6}$ houve uma redefinição do conceito de cultura em termos de recurso, o que permite usá-la para ajudar a resolver os problemas das cidades. Com o crescimento da economia simbólica a cultura torna-se cada vez mais importante na economia urbana e elemento chave na própria estratégia produtiva, uma vez que quase todos os elementos culturais foram sujeitos à mercadorização, isto é, passaram a ser oferecidos segundo a lógica do lucro em mercados descentralizados (Scott, 1997).

A cultura em sentido lato e a economia simbólica são hoje uma importante componente das economias urbanas porque permitem atrair visitantes e investimentos e a sua "produção" cria empregos e tem justificado e orientado muitos investimentos na transformação material das áreas urbanas, seja de iniciativa privada, seja sob formas diversas de colaboração entre o sector público e as organizações da sociedade civil. Zukin (1995) nota que, cada vez mais frequentemente, as operações de "regeneração urbana" tendem a incluir um importante equipamento cultural (frequentemente museus, de que são exemplo a Tate Modern, o Guggenheim de Bilbau ou o MACB em Barcelona) que atrai visitantes e contribui para a valorização das áreas envolventes. A tendência de certas áreas para acolher actividades ligadas à produção cultural, por vezes em articulação com aqueles equipamentos, como sucedeu no El Raval de Barcelona,

6 Em Miles e Paddison, 2005.

7 Cada vez mais a bibliografia inglesa refere redevelopment em vez de regeneration. Prefiro claramente esta expressão mais neutra e mais dirigida à intervenção ao nível do tecido reconstruído ou reurbanizado. 
facilita a instalação desse tipo de actividades e, por vezes, igualmente a nobilitação (gentrification).

A noção de economia cultural ou actividades de produção cultural não é clara. Alguns autores, como Landry e Bianchini (1995), aplicam-na num sentido relativamente estreito de artes (visuais e de espectáculos), comunicação e media, enquanto para Scott (2000) a economia cultural tem a ver com produção artesanal, moda e produção cultural (artes, cinema, mas também restaurantes), tudo actividades com grande desenvolvimento nas áreas centrais, em articulação com a diversificação da procura e intervenções no ambiente construído.

Muitos dos novos residentes procuram o centro histórico das cidades para morar, embora por razões diferentes, e podem desempenhar um papel importante na reabilitação de casas e espaços. Os imigrantes instalam-se em áreas degradadas e desqualificadas da cidade centro ou da periferia onde encontram alojamentos baratos que, no geral, partilham com outros da mesma origem geográfica. Também os estudantes procuram o centro devido à sua grande acessibilidade. Instalam-se em quartos alugados, contribuindo assim para aumentar os rendimentos de populações idosas que habitam nestas áreas, ou alugam apartamentos que partilham. Já os reformados, que se dirigem a cidades pequenas ou médias porque valorizam o património histórico, a ambiência urbana, as vantagens da centralidade que dispensa o uso constante do automóvel, a acessibilidade à diversidade da oferta urbana, são muitas vezes responsáveis pela reabilitação de imóveis ou constituem mercado para esse tipo de alojamentos.

Em diversas cidades começa a verificar-se também a existência de importante procura de habitação nas áreas interiores para grupos favorecidos, capazes de pagar o valor da centralidade, os gentrifiers. Os primeiros ocuparam esses bairros por razões estético-artísticas ou imbuídos de uma certa nostalgia pela cidade da rua e do bairro de que fala Jacobs (1961). Em muitos casos essa acção pioneira, especialmente quando teve capacidade de mobilizar os poderes públicos na preservação e conservação de elementos paisagísticos, acabou por atrair outros grupos, mais endinheirados, e o capital imobiliário. Assiste-se então a investimentos vultuosos na "recuperação" e "reabilitação" de bairros antigos com a consequente oferta de fogos novos ou modernizados de qualidade e preço elevado, acompanhados por restaurantes, actividades no domínio do design e da moda, comércios sofisticados e outros serviços em muitas áreas centrais. Sejam yuppies endinheirados cujo ritmo de vida exige centralidade, sejam os grisalhos também apreciadores da vida cultural do centro, sejam artistas e outros produtores culturais, não há dúvida que o interior da cidade voltou a estar na moda, a ter interesse como área residencial.

Deste modo, as novas procuras em termos de habitação, estão a trazer de volta à cidade centro residentes, todavia em processos susceptíveis de provocar dualização. De um lado grupos favorecidos, activos ou reformados, e residências só ocupadas temporariamente com a função de habitação secundária e, do outro lado, imigrantes, idosos de fracos recursos, muitas vezes na situação 
de reformados, que ocupam casas antigas e degradadas. Os estudantes podem estar num ou noutro lado.

Neste número de Finisterra, Luís Mendes dá conta da nobilitação no Bairro Alto de Lisboa e desmonta a falsa ideia de que hoje se vive um processo de migração de populações dos subúrbios para as áreas centrais. Como em tantos outros aspectos da construção da cidade contemporânea, encontramos também, nas opções de residência, sinais contrários: sob o movimento dominante de periferização notam-se tendências em contra-corrente de procura e valorização de espaços na cidade-centro.

No quadro 1 sintetizamos a procura dos novos residentes das cidades, tanto no que respeita a residência como a comércio e serviços. Em termos de comércio, a presença de estudantes faz multiplicar os franchisings de roupa de marca e estilo jovem mas também as unidades de preços acessíveis, as de artigos e equipamentos de desporto, as livrarias e lojas de venda de discos; os imigrantes estão associados ao comércio étnico, quer pela via empresarial, concentrando-se nalguns ramos, quer como clientes dos restaurantes e estabelecimentos que oferecem bens de primeira necessidade, uma vez que os seus níveis de consumo não são muito altos, pelo menos se encaram a estadia na sociedade de acolhimento como provisória.

Fonseca e Malheiros (2004) analisam o papel dos imigrantes no processo de reestruturação económica e internacionalização secundária das cidades, em alternativa ao processo de globalização da economia associada ao desenvolvimento das empresas transnacionais, tomando como referência a difusão dos restaurantes chineses e indianos em Lisboa. Outros ramos de comércio ligados à imigração que se têm desenvolvido entre nós são supermercados e mercearias de chineses e russos, cabeleireiros que praticam o estilo africano, lojas de mobiliário, brinquedos, quinquilharias e artigos de vestuário. $\mathrm{O}$ nível de empresarialismo não é idêntico nas diversas comunidades, sendo muito maior nos chineses, indianos e paquistaneses, do que nos africanos, e notando-se alguma especialização.

Os restaurantes especializados e outros tipos de comércio étnico podem também contribuir para a atracção de certas áreas das cidades uma vez que entram no leque de bens dos novos consumos culturais.

Na bibliografia encontram-se referências à reabilitação de certos bairros ou ruas, designadamente alguns com localização central mas ocupados por minorias étnicas, depois de um processo de filtering down, para efeitos da sua entrada no mercado do "consumo exótico". As etnoscapes, que Appadurai (1997) define como as paisagens daqueles que constituem o "shifting world in which we live» (citado em Shaw et alia, 2004: 1984), são valorizadas enquanto paisagens urbanas exotizadas para consumo de ócio e turismo. Os restaurantes, algumas lojas de produtos específicos da cultura do grupo residente e mercados de rua têm capacidade de atrair pessoas pertencentes ao mesmo grupo étnico, mas residentes noutras partes da cidade ou em outras cidades, mas também outros interessados em conhecer, partilhar ou usufruir experiências exóticas que, por serem 
vividas no seio daquela comunidade especifica, se apresentam como mais verdadeiras do que as oferecidas por restaurantes semelhantes em qualquer centro comercial ou rua da cidade centro. A própria visita de um bairro étnico, eventualmente com alguma conotação negativa associada (de perigo, por exemplo), pode ser parte da excitação. Para outros, essa visita pode revestir motivações mais generosas de desfazer preconceitos, perceber melhor quem é e como vive "o outro" e ajudar a economia local. Isto ajuda a perceber os "city safaris" organizados em Roterdão (Shaw, et alia, 2004) e mostra como as motivações para o consumo são diferenciadas.

Quadro 1 - Exemplo de novas procuras nas áreas centrais das cidades Table 1 - New demand on the inner city

\begin{tabular}{|c|c|c|c|}
\hline & Residência & $\begin{array}{l}\text { Comércio } \\
\text { e restauração }\end{array}$ & $\begin{array}{l}\text { Serviços } \\
\text { e infra-estruturas }\end{array}$ \\
\hline Estudantes & $\begin{array}{l}\text { Quartos no centro. } \\
\text { Partilha de apartamentos } \\
\text { alugados no centro } \\
\text { ou na periferia }\end{array}$ & $\begin{array}{l}\text { Comércio jovem, } \\
\text { franchisings } \\
\text { Fast food, bares, cafés, } \\
\text { Livrarias e discos }\end{array}$ & $\begin{array}{l}\text { Espectáculos, discotecas, } \\
\text { desporto. } \\
\text { Internet, transportes }\end{array}$ \\
\hline Imigrantes & $\begin{array}{l}\text { Quartos e casas } \\
\text { partilhadas baratas, } \\
\text { degradadas, no centro } \\
\text { ou na periferia; } \\
\text { alojamentos do patrão }\end{array}$ & $\begin{array}{l}\text { Restaurantes e outro } \\
\text { comércio étnico, feiras, } \\
\text { discount }\end{array}$ & $\begin{array}{l}\text { Espaço público, templos. } \\
\text { Telecomunicações } \\
\text { e transferências bancárias }\end{array}$ \\
\hline Turistas & $\begin{array}{l}\text { Hotéis, novas formas } \\
\text { de alojamento turístico } \\
\text { (bed \& breakfast, hotéis } \\
\text { de charme, turismo } \\
\text { de habitação, etc.) }\end{array}$ & $\begin{array}{l}\text { Comércio de artigos } \\
\text { regionais, comércio } \\
\text { de qualidade, } \\
\text { restaurantes variados } \\
\text { Ambientes, património }\end{array}$ & $\begin{array}{l}\text { Espectáculos e serviços } \\
\text { culturais, equipamentos } \\
\text { de desporto (da piscina } \\
\text { ao golfe), visitas guiadas } \\
\text { diferenciadas }\end{array}$ \\
\hline $\begin{array}{l}\text { Quadros } \\
\text { de empresas }\end{array}$ & $\begin{array}{l}\text { Alojamentos de topo } \\
\text { de gama no centro } \\
\text { ou na periferia em áreas } \\
\text { privilegiadas }\end{array}$ & $\begin{array}{l}\text { Comércios } \\
\text { e restaurantes } \\
\text { de qualidade, valor } \\
\text { estético ou simbólico }\end{array}$ & $\begin{array}{l}\text { Lazer e cultura com } \\
\text { nível alto } \\
\text { Internet, auto-estradas } \\
\text { dedicadas }\end{array}$ \\
\hline Reformados & $\begin{array}{l}\text { Casas novas ou } \\
\text { reabilitadas no centro, } \\
\text { residências para idosos }\end{array}$ & $\begin{array}{l}\text { Restaurantes variados; } \\
\text { áreas comerciais como } \\
\text { fonte de passeio }\end{array}$ & $\begin{array}{l}\text { Lazer, desporto } \\
\text { e cultura de nível, } \\
\text { serviços de saúde, jardins } \\
\text { e passeio }\end{array}$ \\
\hline
\end{tabular}

Os turistas favorecem o desenvolvimento do comércio de artigos regionais, dos vinhos ao artesanato, do design aos artigos de qualidade e lojas de marca (Carreras, 2003), enquanto para os idosos as concentrações de comércio são áreas de passeio, mais do que de compras.

Crewe e Beaverstock (1998) assinalam que tanto os centros comerciais como muitas ruas comerciais do centro servem uma cultura de consumo rela- 
tivamente massificada que não interessa os novos consumidores "estéticos". No entanto, o centro com a sua diversidade tem mais possibilidades e está a desenvolver precisamente um comércio de suporte às novas procuras mais exigentes e diferenciadas.

Um grupo de serviços com grande expansão, e em parte associados aos visitantes, são os de restauração, lazer e cultura. Os restaurantes, pese embora a grande diversidade da oferta nas grandes áreas metropolitanas, mostram maior especialização consoante o grupo de novos residentes considerados no quadro 1. A procura crescente de serviços de lazer, cultura, desporto deve-se ao aumento dos rendimentos e dos níveis de escolarização, à redução da semana de trabalho, ao aumento da mobilidade e à importância dos bens culturais na composição das identidades. No domínio das actividades de lazer notam-se grandes diferenças entre actividades relativamente massificadas e de festa permanente, associada à organização sucessiva de eventos ou a recintos do tipo parques de diversões, e o turismo cultural valorizador do património, da ambiência urbana, de certo tipo de manifestações culturais com importante componente de inovação e criatividade, pelo seu grande potencial para os velhos centros.

De notar que o regresso à cidade centro por yuppiers e outros gentrifiers endinheirados ou simplesmente interessados em bens imbuídos de atributos estéticos ou semióticos (Scott, 1997) tem favorecido o desenvolvimento de comércio e serviços de caracter cultural, com qualidade e características únicas, autênticas, e mesmo de algumas actividades industriais (desde a moda e design de objectos, à produção de som e imagens) que também servem visitantes.

Deste modo, encontram-se nos jovens estudantes, nos gentrifiers e nos turistas, os principais animadores de diversas actividades lúdicas e culturais, enquanto os imigrantes, cujo estatuto não é propício à despesa, se destacam principalmente pela ocupação dos espaços públicos nos horários de folga. Invisíveis na maior parte do tempo, porque a trabalhar, os imigrantes, designadamente as mulheres empregadas em serviços domésticos, adquirem grande visibilidade quando se reúnem aos domingos em determinados pontos da cidade ${ }^{8}$.

\section{A TRANSFORMAÇÃO DO AMBIENTE CONSTRUÍDO: MEGAPROJECTOS E GOVERNÂNCIA}

No final do século Xx assistimos ao aparecimento de novas formas na paisagem urbana. Compreendem infra-estruturas de comunicação e transporte e novos produtos imobiliários, espaços de qualidade para acolher empresas, resi-

8 Sobre este aspecto ver o interessante artigo de Yeoh e Huang (1998) sobre as empregadas domésticas Filipinas em Singapura. 
dentes ou actividades de cultura e lazer, muitas vezes de grande dimensão e arquitectura espectacular com forte impacte visual, que contribuem para mudar a imagem de muitos bairros e cidades.

A grande produção imobiliária andou, numa primeira fase, ligada à expansão das actividades empresariais e de serviços e à necessidade de espaços para acomodar o crescimento acelerado das actividades terciárias. Por renovação dos centros tradicionais ou em novos centros ergueram-se torres que simbolizam a cidade das empresas e do capital, como o texto de Hutton (2004) dá conta para o caso de Vancouver e nós analisámos parcialmente em Lisboa (Barata Salgueiro, 1992, 1995).

Posteriormente, operações de reabilitação ou renovação de edifícios antigos começaram a produzir, de forma pontual, na cidade antiga e consolidada, apartamentos de gama alta para grupos endinheirados a quem se oferecia centralidade, vistas, qualidade, perfume da História, segurança e privacidade, quando assumem a forma de condomínios fechados. Em paralelo, surge uma oferta volumosa, produto de importantes operações de regeneração de antigas áreas industriais ou portuárias, de residências, hotéis, escritórios, espaços de recreio e lazer, às vezes em empreendimentos especializados (por exemplo, condomínios residenciais) noutras vezes em complexos de uso misto, porque a habitação e os escritórios se combinam com outras actividades. É talvez nestes últimos que melhor se percebe a pressão da imagem na reformulação das paisagens urbanas.

Esta transformação do ambiente construído decorre de alterações na base económica urbana e traduz mudança nas estratégias dos actores responsáveis pela produção urbana, bem como alteração nas políticas e na forma de gestão urbana. No quadro da reestruturação económica cresceram consideravelmente os investimentos no imobiliário, mercado que adquiriu uma dimensão internacional e passou por uma significativa reestruturação. Harvey $(1985,1987)$ justifica o afluxo de capitais ao sector pelas dificuldades de acumulação na indústria, devido à crise do princípio dos anos 70 , pois estabelece uma ligação entre a produção do espaço construído e crises no processo de acumulação, dando lugar a excesso de liquidez e saídas de capital da esfera produtiva. Do ponto de vista da circulação do capital, os booms imobiliários coincidem com a transferência do capital do circuito primário de acumulação (a esfera produtiva) para o circuito secundário (produção do ambiente construído) ou terciário (actividades de investigação indispensáveis à inovação no circuito produtivo).

Para além da crise na indústria, nas décadas de 70 e 80 do século passado, houve ainda um aumento considerável de capitais em busca de oportunidades de investimento, com a subida do preço do petróleo e o crescimento dos fundos de pensões e os seguros, em articulação com o retrocesso do Estado Providência e os movimentos de privatização da segurança social, nomeadamente nos Estados Unidos, Canadá e Reino Unido. Entretanto, os processos de integração económica, consubstanciados na desregulação dos mercados, e as novas tecnologias favorecem a mobilidade geográfica dos capitais. Os megaprojectos imobiliários, enquanto formas construídas sujeitas a forte valorização, 
tornam-se fonte apetecível de acumulação do capital e atraem investidores nacionais e estrangeiros, pelo que se desenvolveu um mercado de investimento imobiliário à escala internacional que, por sua vez, foi muito importante para financiar as operações de grande dimensão.

O desenvolvimento do sector imobiliário, que permite a produção de grandes projectos, seja de obras púbicas, seja de promoção privada, andou associado a uma importante reestruturação da actividade, principalmente marcada pela internacionalização, profissionalização e segmentação do processo produtivo, aumento da dimensão das empresas e sua reorganização, com maior recurso a consórcios e à subcontratação. A promoção destes projectos faz-se principalmente em sítios extensos, abandonados por efeito da reestruturação económica ou que mantêm usos obsoletos, relativamente centrais, e sítios novos na periferia, mais ou menos externa, de aglomerações que registam importante crescimento. Cite-se, a título de exemplo, em Lisboa, o complexo Amoreiras que substitui uma estação de recolha de autocarros da Carris, o grande edifício sede da CGD sobre as instalações de uma fábrica de cerâmica, o Parque das Nações numa importante zona industrial parcialmente desactivada à beira Tejo, diversos projectos anunciados ou em curso, alguns de arquitectos de renome, para áreas industriais abandonadas na faixa ribeirinha (Alcântara, Braço de Prata), ou para substituir o antigo mercado de fruta, na Avenida das Forças Armadas. A questão da mudança da decrépita Feira Popular para viabilizar uma operação imobiliária e da interrogação sobre o destino do Parque Mayer, ex-enclave de diversão nocturna desde há muito sem qualquer sentido na vida da metrópole, são exemplo da pressão para mudar o uso (e a forma) de espaços importantes e centrais. A re-ocupação das frentes aquáticas, por todo o mundo, reproduz a mesma tendência.

Quanto à ocupação de sítios novos na periferia pode evocar-se o exemplo de Paris com a construção planeada de cidades novas periféricas conectadas à rede de metro por transporte ferroviário de grande velocidade e elevada frequência. As mais conhecidas são, por um lado, a Défense pela importante concentração de escritórios e, por outro lado, Marne-la-Vallée devido à presença do parque de diversões da Disney.

Estes processos de substituição de usos e estruturas construídas tendem a multiplicar-se porque o imobiliário é um bem fixo de longa duração e como a aceleração do período de rotação do capital é um objectivo do capitalismo, há vantagem em apressar a obsolescência dos edifícios de modo a libertar terrenos centrais bem localizados para iniciar novo ciclo de construção e investimento. De facto, «quando vista no contexto da acumulação do capital, a fixidez da organização espacial entra em contradição pois o espaço só pode ser conquistado por meio da produção do espaço... "destruição criativa" da paisagem geográfica pelo capitalismo» (Harvey, 1990a: 258).

Os novos produtos imobiliários são a principal causa da obsolescência das estruturas préexistentes pois, como diz M. Santos (1996: 219) «a tendência actual é de um envelhecimento mais rápido do que antes dos sub-espaços que 
não dispõem dos meios de se actualizar, de um ponto de vista da fluidez». Como mostrámos (Barata Salgueiro, 2002), os processos de produção do espaço comportam a desvalorização intencional das estruturas herdadas, onde cresce rapidamente a diferença entre valor do edifício e o do terreno livre no mercado (diferença entre a renda capitalizada actual e potencial), o chamado rent gap, porque os novos edifícios e localizações surgem como os sítios mais adequados para os negócios, os que oferecem maior qualidade de vida às famílias, os que melhor respondem às necessidades do consumo e propiciam maiores economias.

De facto, a produção hegemónica da cidade procura viabilizar de modo eficiente a produção económica do espaço pelo tempo. Por isso arrasa os lugares do tempo lento e substitui-os por novas formas. Deste modo, assiste-se a importantes operações de renovação ou revalorização em áreas centrais de muitas cidades.

As intervenções em grande escala no tecido urbano beneficiam dos modelos de governo de tipo empresarial, mais sensíveis ao plano económico e interessados em captar investimentos, que viabilizam ou colaboram nestes empreendimentos, assumindo, com frequência, os maiores riscos.

A maior liberdade locativa das actividades, a mobilidade internacional dos capitais e o crescimento do turismo, num quadro de expansão das ideologias neoliberais, convergem no sentido do desenvolvimento da concorrência entre territórios para captar investimentos, visitantes, empregos. Para lhes responder, a gestão urbana evoluiu de estratégias meramente gestionárias para estratégias de tipo empresarial num processo que Harvey foi dos primeiros a identificar. Estas últimas obrigam a políticas pró-activas de promoção e marketing, de valorização dos recursos locais e criação de novos ao serviço delas, de investimentos a nível da imagem. A centralidade dos factores não económicos nas políticas desenvolvidas no quadro da gestão local de tipo empresarial explica a existência de fortes laços entre inovação e marketing, com crescimento da importância da reconstrução da imagem e das representações na formulação das políticas urbanas e nas tentativas para melhorar as condições oferecidas pelas cidades, as quais incluem os aspectos culturais e a modernização de infra-estruturas, em combinação com políticas de limitação do crescimento suburbano retendo no centro residentes de classes médias e altas e emprego, numa cidade compacta e com qualidade de vida (McCann, 2004).

Para Harvey (1997), as cidades competem em quatro grandes campos: o da divisão internacional do trabalho, portanto mostrando vantagens em termos de produção de bens e de serviços; na divisão espacial do consumo para atrair turistas e reformados, com reflexo em estratégias de regeneração urbana com o foco na cultura, entretenimento, espectáculo, valorização da imagem; no campo do comando da alta finança, governo ou processamento da informação, o que envolve a construção de infra-estruturas de comunicação e transporte caras; e pela redistribuição de financiamentos efectuada pelo estado central. Todas as cidades e regiões competem por esta última. Quanto às outras, a divisão espa- 
cial do consumo é a que se mostra mais acessível no curto prazo e daí a sua grande generalidade. Deste modo, assistimos a investimentos consideráveis na reconversão de áreas abandonadas, valorização do património histórico, produção de edifícios marcantes, modernização de infra-estruturas, isto é, investimentos na construção do lugar através do ambiente construído e upgrade da imagem associada à cidade. Verifica-se uma tendência para a substituição de imagens negativas de poluição, métodos arcaicos, declínio, insegurança por imagens positivas de modernidade, progresso, cultura, animação (vida), inovação e tecnologia.

As actividades de lazer e os equipamentos culturais desempenham sempre um papel chave nestas intervenções a ponto de Miles (2005) considerar que existe um sentido de cultura específico dos espaços pós-industriais objecto de regeneração em que se confundem os dois sentidos de cultura antes referidos. Ele é característico de grupos que, embora diversos, têm rendimentos que lhes dão acesso aos novos espaços e bens culturais.

Para Richards et alia $(2004,1932)$ o aumento da concorrência entre cidades leva ainda à adopção de estratégias que transformem o capital cultural fixo em vantagem competitiva ao acolher eventos culturais ou mesmo construir projectos marcantes de referência, de que museus ou centros de congressos são exemplo. A organização de eventos é um modo de rentabilizar algumas destas infra-estruturas.

De um modo geral, acolher eventos ajuda a melhorar a imagem da cidade no exterior, de "pô-la no mapa" porque o acontecimento é mencionado nos media e quanto mais amplo for o alcance do evento, maior cobertura mediática recebe. Depois, a tendência para a sua repetição pode converter a cidade numa festa ou festival permanente (Paddison, 1993).

Estes acontecimentos servem também de pretexto para levar a cabo a reconversão de certas áreas contribuindo para acelerar a formação dos grupos de investidores, e para reunir capitais, por exemplo, dotações extraordinárias do estado central ou mesmo ajudas estrangeiras. De notar ainda que o seu carácter excepcional justifica mais facilmente a expulsão de residentes e actividades que ocupavam a área.

O próprio governo é, com frequência, responsável pelo desencadear de operações de regeneração urbana quando não é o promotor directo de grandes equipamentos e infra-estruturas de transporte e comunicação inseridas numa estratégia de valorização da cidade e da sua imagem. No entanto, estas políticas são facilitadas pela evolução da governância no sentido de um maior envolvimento do sector privado. Para Harvey (1997), o poder para reorganizar a vida urbana está na governância, através de amplas coligações de forças no seio das quais o governo local tem principalmente um papel de coordenador e de facilitador. Estamos perante um novo tipo de empresarialismo que tem como peça central as parcerias público-privado com o objectivo de atrair financiamentos e emprego; a acção destas parcerias é empresarial porque especulativa, portanto envolvendo riscos, com frequência assumidos pelo sector público. 
Os megaprojectos requerem uma rede de infra-estruturas (em termos de acessibilidade, abastecimento de energia e água, telecomunicações) que muitas vezes as áreas interiores das cidades não possuem ou, quando possuem, estão antiquadas. Deste modo, assistiu-se também a importantes investimentos na modernização de infra-estruturas em áreas que se destinam a acolher projectos de qualidade, muitas vezes à custa do serviço prestado a outras áreas.

As "estradas inteligentes" com vias de acesso condicionado, tipo via verde, as áreas equipadas com redes de fibra óptica de alta velocidade, o próprio fornecimento de água com débitos e características quase personalizadas para o edifício ou complexo, as passagens aéreas ou subterrâneas entre edifícios são fonte de valorização destes espaços onde a acumulação se encontra facilitada. Assim se vem a transformar o modelo de fornecimento de infra-estruturas e de alguns serviços, igualitário e característico da cidade Moderna, a favor de um modelo que favorece a dualização ou mesmo a fragmentação, porque opõe áreas privilegiadas a um território extenso e mal servido, como Amin e Graham (1997), Graham e Marvin (2001), Vigar et alia (2005) têm mostrado. As infra-estruturas suportam a complexa reestruturação da vida urbana, dos estilos de vida e paisagens com processos de fragmentação e recombinação de usos e funções, entre e dentro das cidades. As vias rápidas que dão acessibilidade e cercam alguns dos novos enclaves tornam praticamente impossível o seu acesso, excepto o que é feito de automóvel. De facto, a construção de espaços de mobilidade de grande débito nuns lugares e para algumas pessoas traduz-se em barreira para outros que não lhes têm acesso, pois fazem parte dos processos sócio-técnico-culturais de produção diferenciada do urbano, de valorização e desvalorização. O novo modelo de fornecimento é também instrumento da diferenciação do território urbano e está na base do que Graham e Marvin (2001) chamam splintering urbanism e outros, como nós, de "cidade fragmentada" (Barata Salgueiro, 1997).

Uma consequência preocupante destes processos é a construção de uma cidade menos aberta e menos solidária onde se identificam novas formas de segregação.

As novas formas que fazem também a cidade dos serviços, das torres de escritórios inteligentes, dos parques de empresas, dos centros de congressos, dos centros comerciais, dos parques temáticos e desportivos, dos condomínios residenciais, vão polarizar as novas centralidades, articuladas numa estrutura reticulada, e servir de suporte material a novas vivências, traduzidas em novas espacialidades e modos diferentes de usar o tempo. Diversos autores, na sequência de Harvey, alertam para o facto do investimento nestes grandes projectos e nas infra-estruturas que os viabilizam ser feito à custa da quebra no investimento em projectos que melhorariam as condições de vida e de trabalho dos residentes. Não é fácil contabilizar os custos e benefícios destas operações, especialmente as de carácter efémero, como a bibliografia recente vem mostrando, mas também não é desprezível ignorar o seu papel, contribuindo para o aumento da auto-estima dos residentes. 


\section{REFERÊNCIAS}

AA VV CML (2004) Habitação e Mercado Imobiliário na AML. Estudo Desenvolvido pelo CEPCEP (Centro de Estudos dos Povos e Culturas de Expressão Portuguesa) para a CML e EPUL sob coordenação de M. Lages et alia. Câmara Municipal de Lisboa. Licenciamento Urbanístico e Planeamento Urbano. Lisboa.

Appadurai A (1997) Modernity at large. Cultural aspects of globalization. University of Minnesota Press. Minneapolis.

Ascher F (2004) Les nouveaux principes de l'urbanisme. Ed. De l'Aube (1. a ed. 2001). Paris.

Ascher F (2001) Metapolis. Acerca do futuro da cidade. Celta. Oeiras. (ed. Francesa de 1995).

Amin A, Graham S (1997) The ordinary city. Transactions of the Institut of British Geographers, 22(4): 411-429.

Barata Salgueiro T (1992) O mercado de escritórios em Lisboa. Estudos de Economia, 13(1): 3-27.

Barata Salgueiro T (1995) A oferta de escritórios em Lisboa num contexto de internacionalização. Actas do VI Colóquio Ibérico de Geografia, Porto: 39-46.

Barata Salgueiro T (1997) Lisboa metrópole policêntrica e fragmentada. Finisterra - Revista Portuguesa de Geografia, XXXII(63): 179-190.

Barata Salgueiro T (2002) Espacialidades e Temporalidades nas áreas urbanas. Olhares sobre o Território e a Espacialidade. Lisboa, CEG, Estudos de Geografia Humana e Regional n. ${ }^{\circ}$ 45: 25-42.

Bourdieu P (1979) La Distinction. Critique sociale du jugement. Ed. de Minuit, Paris.

Cachinho H (1996) Evolução da procura: perfil dos consumidores e hábitos de consumo. In Barata Salgueiro T, Do Comércio à distribuição. Roteiro de uma Mudança. Celta, Oeiras: 33-50.

Cachinho H (1999) Geografias do consumo. Rotas exploratórias e novas linhas de rumo. Inforgeo, 14: $157-178$.

Cachinho H (2002) O comércio retalhista português. Pós-Modernidade, consumidores e espaço. Gepe e Observatório de Comércio. Lisboa.

Cachinho H (2006) Consumactor: da condição do indivíduo na cidade pós-moderna. Finisterra Revista Portuguesa de Geografia, XLI(81): 29-50.

Campbell C (1987) The romantic ethic and the spirit of modern consumerism. B. Blackwell. Oxford.

Campbell C (dir.) (2003) Atles comercial de Barcelona. Ajuntamento de Barcelona. Barcelona.

Castles S (2005) Globalização, transnacionalismo e novos fluxos migratórios. Dos trabalhadores convidados às migrações globais. Fim de Século. Lisboa.

Castles S, Miller M J (2003) The age of migration: international population movements in the modern world. Macmillan. Basingstoke, Palgrave.

Castro M (2006) Novas procuras e novas formas de comércio os centros tradicionais. O caso de Portalegre. Dissertação de Mestrado em Geografia Humana / Estudos Urbanos. Lisboa, Faculdade de Letras da Universidade de Lisboa (policopiado).

Chaney D (1996) Lifestyles. Routledge. Oxford.

Clark D (1996) Urban world. Global city. Routledge. London.

Clarke D B (1997) Consumption and the city, modern and postmodern. International Journal of Urban and Regional Research, 21(2):219-237.

Cravidão F (1991) Residência secundária e revalorização do espaço rural. In V Colóquio Ibérico de Geografia. Actas, Ponencias y Comunicaciones. Léon. Universidad de Léon: 359-365. 
Crewe L, Beaverstock J (1998) Fashioning the city. Cultures of consumption in contemporary urban spaces. Geoforum, 29(3): 287-308.

Ferrão J, Domingues A (1994) Portugal: as condições territoriais de um processo de terciarização vulnerável. Finisterra - Revista Portuguesa de Geografia, XXIX(57): 5-42.

Fonseca M L, Malheiros J M (2004) Immigration and globalization from below: the case of ethnic restaurants in Lisbon. Finisterra - Revista Portuguesa de Geografia, XXXIX(77): 129-156.

Garreau J (1991) Edge city. Life on the new frontier. Anchor Books, New York.

Glennie P (1998) Consumption, consumerism and urban form: historical perspectives. Urban Studies, 35(5-6): 27-951.

Graham S, Marvin S (2001) Splintering urbanism. Networked infrastructures, technological mobilities and the urban condition. Routledge. Londres.

Gresillon M (1996) La ville et nous, géographes. L’Information Géographique, 60: 81-85.

Hall P (2000) Creative cities and economic development. Urban Studies, 37(4): 639-649.

Hall P (2003) The end of the city? "The repport of my death was an exaggeration". The City, 7(2): 141-152.

Hall P, Hubbard Ph (1996) The entrepreneurial city: new urban politics, new urban geographies? Progress in Human Geography, 20(2): 153-174.

Harvey D (1985) The urbaniztion of capital. Studies in the history and theory of capitalist urbanization. Blackwell. Oxford.

Harvey D (1987) Flexible accumulation through urbanization. Reflections on 'post-modernism' in the American city. Antipode, 19(3): 260-286.

Harvey D (1989) From managerialism to entrepreneurialism. The transformation in urban governance in late capitalism. Geografiska Annaler, ser B (71-B): 3-17.

Harvey D (1990a) The condition of postmodernity. Blackwell, Oxford.

Harvey D (1990b) Between space and time: reflections on geographical imagination. Annals of the Association of American Geographers, 80: 418-434.

Harvey D (1997) Justice, Nature and the Geography of Difference. Blackwell, Oxford.

Hutton Th A (2004) Post-industrialism. Postmodernism and the reproduction of Vancouver central area: retheorising the $21^{\text {st }}$ century city. Urban Studies, 41(10):1953-1982

Jacobs J (1961) The death and life of great American cities. Vintage Books, Nova Iorque.

Landry Ch, Bianchini F (1995) The Creative City. Demos, Londres.

Lash S, Urry J (1994) Economies of signs and space. Sage, Londres.

Lewis P F (1983) The Galactic Metropolis. In Platt R H, Macinko G (eds) Beyond the Urban Fringe. University of Minnesota Press, Minneapolis: 23-49.

Ley D (2003) Artists, aestheticisation and the field of gentrification. Urban Studies, 40(12): 2527$-2544$

McCann E (2004) Best places. Interurban competition, quality of life and popular media discourse. Urban Studies, 41(10): 1909-1929.

Mendes L (2006) A nobilitação urbana no Bairro Alto: análise de um processo de recomposição sócio-espacial. Finisterra - Revista Portuguesa de Geografia, XLI(81) (este volume).

Miles S (2005) Interruptions: testing the rhetoric of culturally led urban development. Urban Studies, 42(5/6): 889-911. 
Miles S, Paddison R (1998) Urban consumption. An historical note. Urban Studies, 35(5/6): 815$-823$.

Miles S, Paddison R (2005) The rise and rise of culture-led urban regeneration. Urban Studies 42(5/6):833-839.

Moulaert F et al. (2004) Urban renaissance: from physical beautification to social empowerment. Lessons from Bruges cultural capital of Europe 2002. City, 8(2): 229-235.

Paddison R (1993) City marketing, image reconstruction and urban regeneration. Urban Studies, 30: 339-350.

Phillips E B (1996) City lights. Urban-suburban life in the global society. Oxford University Press, Nova Iorque e Oxford.

Phillips M (2004) Other geographies of gentrification. Progress in Human Geography, 28(1): 5-30.

Richards G, Wilson J (2004) The impact of cultural events on city image: Rotterdam cultural capital of Europe 2001. Urban Studies 41(10): 1931-51.

Santos M (1996) A natureza do espaço. Técnica e tempo. Razão e emoção. Hucitec, São Paulo.

Sarmento J (1998) Geografia Cultural e Geografia do Turismo. Configurações para o final da década de 90. Inforgeo 12/13:163-172.

Scott A J (1996) The craft, fashion, and cultural-products industries of Los Angeles. Competitive dynamics and policy dilemmas in a multisectoral image-producing complex. Annals of the Association of American Geographers, 86(2): 306-323.

Scott A J (1997) The cultural economy of cities. International Journal of Urban and Regional Research, 21(2): 323-339.

Scott A J (2000) The Cultural Economy of Cities. Sage, London.

Shaw S, Bagwell S, Karmowska J (2004) Ethnoscapes as spectacle: reimaging multicultural districts as new destinations for leisure and tourism consumption. Urban Studies, 41(10): 19832000.

Shields R (1999) Culture and the economy of cities. European Urban and Regional Studies, 6(4): 303-311.

Sjoholt P (1999) Culture as a strategic development device: the role of 'european cities of culture' with particular reference to Bergen. European Urban and Regional Studies, 6(4): 339-345.

Soja E W (1994) O desenvolvimento metropolitano pós-moderno nos EUA: virando Los Angeles pelo avesso. In Santos M et alia (ed.) Território, Globalização e Fragmentação. São Paulo. Hucitec/Anpur.

Soja E W (1995) Postmodern urbanization: the six restructurings of Los Angeles. In Watson S, Gibson K (eds) Postmodern cities and spaces. Blackwell, Cambridge, Mass.:125-137.

Soja E W (2003) Writing the city spatially. City, 7(3): 269-280.

Taylor I (2000) European ethnoscapes and urban redevelopment. The return of Little Italy in $21^{\text {st }}$ century Manchester. City, 4(1): 27-42.

Thrift N (1997) Cities without modernity, cities with magic. Scottish Geographical Magazine, 113(3): 138-149.

Turner B S (1989) Status. Ed. Estampa, Lisboa.

Vigar G, Graham S, Healey P (2005) In search of the city in spatial strategies. Past legacies, future imagings. Urban Studies, 42(8): 1391-1410.

Veblen Th (1970) Théorie de la classe de loisir. Gallimard, Paris (1. ${ }^{\mathrm{a}}$ ed. Inglesa de 1899). 
Viard J (1994) La Société d'archipel ou les territories du village global. Éditions de l'Aube. Paris.

Waitt G (1999) Playing games with Sydney. Marketing Sydney for the 2000 Olympics. Urban Studies, 36(7): 1055-1077.

White P (2002) Migration and mediterranean urban societies: policy, contexts and concerns. In Fonseca M L et al (eds) Immigration and place in Mediterranean metropolises. Metropolis Portugal/Fundação Luso-Americana para o Desenvolvimento, Lisboa: 13-30.

Yeoh B, Huang S (1998) Negotiating public space. Strategies and styles of migrant female domestic workers in Singapore. Urban Studies, 35(3): 583-602.

Zukin S (1995) The culture of cities. Blackwell. Oxford.

Zukin S (1998) Urban lifestyles. Diversity and standardization in spaces of consumption. Urban Studies, 35(5-6): 825-839. 